\title{
A Study of Euthanasia and Related Values in Taiwan
}

\author{
Wen-Shai Hung \\ Department of Business Administration, Providence University, Taiwan \\ Email: wshung@pu.edu.tw
}

How to cite this paper: Hung, W.-S. (2016) A Study of Euthanasia and Related Values in Taiwan. Modern Economy, 7, 1543-1554. http://dx.doi.org/10.4236/me.2016.713138

Received: August 22, 2016

Accepted: November 28, 2016

Published: December 1, 2016

Copyright (๑) 2016 by author and Scientific Research Publishing Inc. This work is licensed under the Creative Commons Attribution International License (CC BY 4.0).

http://creativecommons.org/licenses/by/4.0/

\section{(c) (i) Open Access}

\begin{abstract}
This paper analyses the factors influencing euthanasia and related values in Taiwan. The data used are from the 2015 Survey Research on Attitudes towards the Death Penalty and Related Values in Taiwan, which focused on knowledge, attitudes towards the death penalty, and the concepts of social, political, and law values. The sample ages are from 21 to 94 . The method used is probit modelling for examining the influences on euthanasia issues in Taiwan. The main empirical results find that older people, persons with higher educational attainment, those who favour abolition of the death penalty and do not oppose divorce, abortion, same-sex relationships, and putting down homeless' cats or dogs are more likely to approve of the use of euthanasia to end their lives. In contrast, Mainlanders, people who support the death penalty and favour long-term prison sentences are less likely to support the use of euthanasia.
\end{abstract}

\section{Keywords}

Euthanasia, Divorce, Death Penalty, Probitmodel

\section{Introduction}

According to the government report of Taiwan (2014), the average life expectancy from birth has gradually increased from 77.3 years in 2003 to 80.0 years in 2013. The average healthy life expectancy has also increased, from 69.7 years in 2003 to 71.1 years in 2013. This suggests that most elderly Taiwanese were not happy due to poor health in later life, particularly those living with disabling conditions. The question then arises as to how people make the decision to end their lives: timely death or good death? This issue is important and merits further research. It is not only a personal event, but also has implications for social security systems and human rights. 
In the ancient Chinese classic "Book of History", also known as the "Classic of History", there are "Five Blessings", also known as the "Five Happiness" or "Five Good Fortunes", which refer to longevity, wealth, health and composure, love of virtue, and the desire to die a natural death in old age (or timely death). In addition, Figure 1 shows an illustration of five bats and one Chinese character-ten thousand years. The five bats represent five lucky things, because the Chinese pronunciations of "bat" and "lucky" are similar. According to Chinese tradition successful people pursue these five things-long life, wealth, good health, good behaviour, and timely death-relentlessly throughout their whole life. The other Chinese character represents eternity. If people have these five things, they will be represented as more successful throughout their whole life in traditional Chinese society [1].

Therefore, long life may be not equal to good life. From a religious perspective, people may prefer to die at their "appointed time" regardless of their state of health. But from a social perspective, individuals may choose to have a good death and release from the painful body or torment in their later lives, and they can also save a lot of medical resources.

Most previous studies of euthanasia issues focused on hospice and palliative care, such as Chiu [2] who presented the ideal model of care at the end of life in Taiwan. In particular, the number of terminal cancer patients and the medical expenditure for the end of life services in Taiwan have increased in recent years; palliative care has been advocated as a moral responsibility of medical professionals [2].

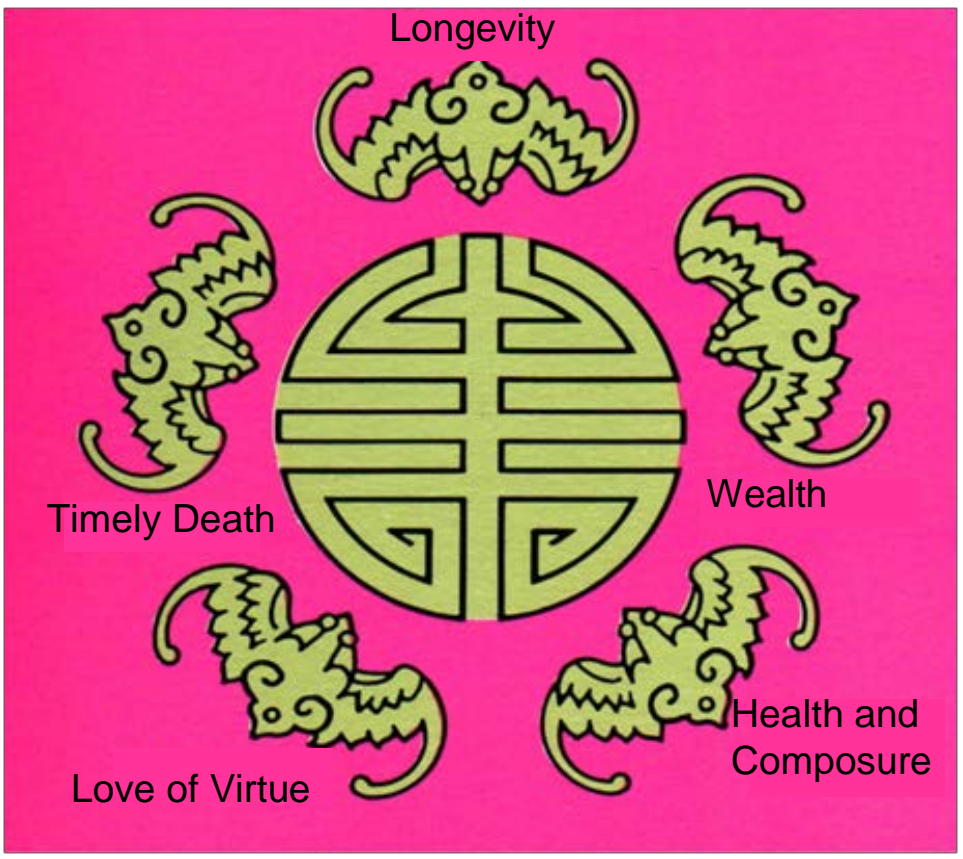

Figure 1. Five Lucky Things in Traditional Chinese Culture Source: Hung, Wen-Shai [1]. An economic analysis of retirement decision in Taiwan. Durham theses, Durham University. Available at Durham E-Theses Online: http://etheses.dur.ac.uk/2114/, p. 28. 
Furthermore, Lin, et al. [3] explored whether regular exercise may prolong life expectancy of the elderly and increase the proportion of active life expectancy in Taiwan. The data used were from the 1989-2007 Taiwan Longitudinal Study on Aging (TLSA) and they found that regular exercisers have longer life expectancy and higher proportion of active life expectancy, but the inactive life expectancy was not significantly lower. They suggested that exercise can prolong life and help the elderly retain an active state.

However, few empirical studies have considered the individual decisions and social values of euthanasia in Taiwan. This paper tries to fill this gap and investigates the factors influencing good death or timely death in Taiwan. The paper is organized as follows. Section 2 presents the concepts of euthanasia and some facts of healthy life expectancy in Taiwan. Section 3 describes the data source. Section 4 presents the model and estimation. Section 5 discusses the empirical results. Section 6 concludes.

\section{The Concepts of Euthanasia and Some Facts of Healthy Life Expectancy in Taiwan}

The term euthanasia is a compound of two Greek words-eu and thanatos meaning, literally, a good death [4]. The concept of a good death has been understood over the history of philosophical thinking, in which values, circumstances and actions have been assigned to this concept and debates have continued as to how it has been considered by cultural, historical, social and religious factors [5].

According to the report of the 2015 Quality of Death Index by the Economist Intelligence Unit (EIU), everyone hopes for a good death or rather "a good life to the very end". They evaluated 80 countries using 20 quantitative and qualitative indicators across five categories: the palliative and healthcare environment, human resources, the affordability of care, the quality of care and the level of community engagement. They found that income levels are a strong indicator of the availability and quality of palliative care, with wealthy countries clustered at the top of the Index. The leading countries with a high quality of death share several characteristics including: 1) a strong and effectively implemented national palliative care policy framework; 2) high levels of public spending on healthcare services; 3 ) extensive palliative care training resources for general and specialised medical workers; 4) generous subsidies to reduce the financial burden of palliative care on patients; 5) wide availability of opioid analgesics; 6) strong public awareness of palliative care. Finally, the United Kingdom has the best quality of death, and rich nations tend to rank highest. Australia and New Zealand come second and third overall, and four other comparatively rich Asia-Pacific countries achieve rankings in the top 20: Taiwan at position six, joined by Singapore at 12, Japan at 14, and South Korea at 18 [6].

Taiwan is one of the world's fastest aging populations, the ratio of the elderly population in 2010, 2020, 2030 will reach $10.5 \%, 16.1 \%$ and $24.5 \%$; it is projected that the elderly population ratio in 2050 will be as high as $35.5 \%$ of the total [7].

In addition, according to the report of the Directorate General of Budget, Accounting and Statistics (DGBAS), the male life expectancy at birth gradually increased from 73.8 
years in 2000 to 76.7 years in 2013 and the female life expectancy at birth also gradually increased from 79.6 years to 83.3 years during the same period as shown in Table 1 . However, the male healthy life expectancy at birth only increased from 66.8 years in 2000 to 68.7 years in 2012, and for the females from 71.0 to 73.3 years. This indicates that people may live longer but in poor health, including being overweight and smoking and drinking, can let them easily have the problems of heart disease and stroke. Therefore, the unhealthy life expectancy at birth also increased for their later life as shown in Table 1.

\section{Data}

\subsection{Data Source}

The data set used is from the 2015 Survey Research on Attitudes towards the Death Penalty and Related Values in Taiwan by Hei-yuan Chiu, which focused on knowledge, attitudes towards the death penalty, and the concepts of social, political, and law values. This paper only examines the factors influencing euthanasia issues in Taiwan. The sample ages are from 21 to 94 . The total sample has 2039 observations, but the effective sample only has 1136 observations, who have completely answered all the questions

Table 1. Unhealthy life expectancy at birth in Taiwan from 2000 to 2012.

\begin{tabular}{|c|c|c|c|c|c|c|c|c|c|}
\hline \multirow{2}{*}{ Year } & \multicolumn{3}{|c|}{$\begin{array}{l}\text { Life expectancy at } \\
\text { birth }(\mathrm{A})\end{array}$} & \multicolumn{3}{|c|}{$\begin{array}{l}\text { Healthy life expectancy at } \\
\text { birth (B) }\end{array}$} & \multicolumn{3}{|c|}{$\begin{array}{c}\text { Unhealthy life expectancy at } \\
\text { birth }=(A)-(B)\end{array}$} \\
\hline & Total & Male & Female & Total & Male & Female & Total & Male & Female \\
\hline 2000 & 76.5 & 73.8 & 79.6 & 68.7 & 66.8 & 71.0 & 7.8 & 7 & 8.6 \\
\hline 2001 & 76.8 & 74.1 & 79.9 & 68.9 & 66.7 & 71.7 & 7.9 & 7.4 & 8.2 \\
\hline 2002 & 77.2 & 74.6 & 80.2 & 69.1 & 66.9 & 71.7 & 8.1 & 7.7 & 8.5 \\
\hline 2003 & 77.4 & 74.8 & 80.3 & 69.7 & 67.6 & 72.3 & 7.7 & 7.2 & 8 \\
\hline 2004 & 77.5 & 74.7 & 80.8 & 69.4 & 67.1 & 72.0 & 8.1 & 7.6 & 8.8 \\
\hline 2005 & 77.4 & 74.5 & 80.8 & 69.4 & 67.1 & 72.2 & 8 & 7.4 & 8.6 \\
\hline 2006 & 77.9 & 74.9 & 81.4 & 69.9 & 67.6 & 72.7 & 8 & 7.3 & 8.7 \\
\hline 2007 & 78.4 & 75.5 & 81.7 & 70.1 & 67.9 & 72.7 & 8.3 & 7.6 & 9 \\
\hline 2008 & 78.6 & 75.6 & 81.9 & 70.2 & 68.0 & 72.9 & 8.4 & 7.6 & 9 \\
\hline 2009 & 79.0 & 76.0 & 82.3 & 70.5 & 68.3 & 73.0 & 8.5 & 7.7 & 9.3 \\
\hline 2010 & 79.2 & 76.1 & 82.5 & 70.7 & 68.5 & 73.2 & 8.5 & 7.6 & 9.3 \\
\hline 2011 & 79.1 & 76.0 & 82.6 & 70.1 & 67.8 & 72.7 & 9 & 8.2 & 9.9 \\
\hline 2012 & 79.5 & 76.4 & 82.8 & 70.8 & 68.7 & 73.3 & 8.7 & 7.7 & 9.5 \\
\hline 2013 & 79.9 & 76.7 & 83.3 & - & - & - & - & - & - \\
\hline
\end{tabular}

Source: Directorate-General of Budget, Accounting and Statistics. 2014. Social Indicators 2013, Executive Yuan, Taiwan, Republic of China. Available from the website as follow:

http://www.stat.gov.tw/ct.asp?xItem $=36477 \& \mathrm{ctNode}=538 \& \mathrm{mp}=4$. 
about the euthanasia issues. In particular, the samples of euthanasia answering are missed 175 observations, the individual earnings variable missed 239 observations, and the household income variable also missed 489 observations.

\subsection{Variables Specification}

Probit analysis examines the influences on euthanasia issues in Taiwan. Hence the dependent variable is simply specified as $y=1$ if the respondents or their family agree with euthanasia and zero otherwise. Table 2 shows that $76.2 \%$ observations agree with euthanasia. The explanatory variables include 1) Individual characteristic variables: age, gender, race, and education. 2) Economic variables: individual earnings and family income. 3) Social valuation variables: agree with the issues of long-term imprisonment, Buddhist, divorce, abortion, homosexuality, abolishing the death penalty, and putting down the stray dogs and cats. A full definition of the variables and summary statistics of the sample are given in Table 2.

\section{Empirical Specification}

This paper uses Probit modelling to examine the influences on euthanasia issues in Taiwan. Let $y$ represent the choice of euthanasia issues ( $y=1$ if agree with euthanasia, 0 otherwise) and let the two outcomes be described by the state-specific utilities $U_{y}^{*}[8][9]:$

$$
\begin{gathered}
U_{y=1}^{*}=x^{\prime} \beta_{1}+u_{1} \\
U_{y=0}^{*}=x^{\prime} \beta_{0}+u_{0}
\end{gathered}
$$

where $x^{\prime}$ represents a common set of control variables, $\beta_{0}$ and $\beta_{1}$ are vectors of unknown parameters, $u_{0}$ and $u_{1}$ represent unobservable (state-specific) taste components. Under this characterisation, an individual will agree with euthanasia if the utility to be got when agreeing with euthanasia (denoted $U_{y=1}^{*}$ ) exceeds the utility to be had when not agreeing with euthanasia (denoted $U_{y=0}^{*}$ ). An individual will agree with euthanasia if $U_{y=1}^{*}>U_{y=0}^{*}$, and therefore the decision to agree with euthanasia $y=1\left(U_{y=1}^{*}-U_{y=0}^{*}>0\right)$

Consequently the observation rule (1) and (2) can be rewritten as:

$$
\begin{aligned}
y & =1\left(U_{y=1}^{*}>U_{y=0}^{*}\right) \\
& =1\left(x \beta_{1}+u_{1}>x \beta_{0}+u_{0}\right) \\
& =1\left[\left(u_{1}-u_{0}\right)>-x\left(\beta_{1}-\beta_{0}\right)\right]
\end{aligned}
$$

Clearly, both sets of parameters $\beta_{0}$ and $\beta_{1}$ cannot be identified. However, the difference $\beta_{1}-\beta_{0}$ can be identified, and implicitly parameterise the choice model as: $y=1\left(y^{*}>0\right)$, where $y^{*}=x^{\prime}\left(\beta_{1}-\beta_{0}\right)+\left(u_{1}-u_{0}\right)=x^{\prime} \beta+u$ Maximum likelihood estimation (hereafter, MLE) considers the probability of observing a sample of behavioural outcomes and characteristics. Consider a sample of $n$ observations $\left\{y_{i}, x_{i}\right\}$ drawn at random from a population, where $y_{i}$ is binary. Assuming the observability criterion $y_{i}=1\left(y_{i}^{*}>0\right)$ for a latent variable Equation of the form $y_{i}^{*}=x_{i}^{\prime} \beta+u_{i}$ and, assuming 
Table 2. Descriptive statistics of variables.

\begin{tabular}{|c|c|c|c|}
\hline Variables & Description & Mean & Standard Error \\
\hline Euthanasia & $1=$ Agree with euthanasia, $0=$ Otherwise & 0.762 & $(0.425)$ \\
\hline Age 1 & $1=$ Aged from 21 to $30,0=$ Otherwise & 0.187 & $(0.390)$ \\
\hline Age 2 & $1=$ Aged from 31 to $40,0=$ Otherwise & 0.231 & $(0.421)$ \\
\hline Age 3 & $1=$ Aged from 41 to $50,0=$ Otherwise & 0.241 & $(0.428)$ \\
\hline Age 4 & $1=$ Aged from 51 to $60,0=$ Otherwise & 0.196 & $(0.397)$ \\
\hline Age 5 & $1=$ Aged from 61 to $70,0=$ Otherwise & 0.094 & $(0.292)$ \\
\hline Age 6 & $1=$ Aged from 71 to $94,0=$ Otherwise & 0.049 & $(0.216)$ \\
\hline Gender & $1=$ Men, $0=$ Women & 0.549 & $(0.498)$ \\
\hline Race1 & $1=$ Fujianese, $0=$ Otherwise & 0.735 & $(0.441)$ \\
\hline Race 2 & $1=$ Hakka, $0=$ Otherwise & 0.117 & $(0.322)$ \\
\hline Race 3 & $1=$ Aboriginal, $0=$ Otherwise & 0.011 & $(0.102)$ \\
\hline Race 4 & $1=$ Mainlander, $0=$ Otherwise & 0.130 & $(0.337)$ \\
\hline Race 5 & $1=$ New people, $0=$ Otherwise & 0.007 & $(0.083)$ \\
\hline Edu 1 & $1=$ Informal, $0=$ Otherwise & 0.012 & $(0.110)$ \\
\hline Edu 2 & $1=1-6$ years of schooling, $0=$ Otherwise & 0.078 & $(0.269)$ \\
\hline Edu 3 & $1=7-9$ years of schooling, $0=$ Otherwise & 0.109 & $(0.311)$ \\
\hline Edu 4 & $1=10-12$ years of schooling, $0=$ Otherwise & 0.269 & $(0.444)$ \\
\hline Edu 5 & $1=13-16$ years of schooling, $0=$ Otherwise & 0.437 & $(0.496)$ \\
\hline Edu 6 & 17 years and over of schooling, $0=$ Otherwise & 0.094 & $(0.292)$ \\
\hline Earnings & Earnings = log (individual average earnings) & 10.297 & $(0.858)$ \\
\hline Income & Income $=\log$ (household average income) & 11.119 & $(0.789)$ \\
\hline Longprison & $\begin{array}{l}1=\text { Agree with long-term imprisonment, } \\
\qquad 0=\text { Otherwise }\end{array}$ & 0.332 & $(0.313)$ \\
\hline Buddhist & $1=$ Religions in Buddhism, $0=$ Otherwise & 0.239 & $(0.427)$ \\
\hline Divorce & $1=$ Agree with divorce, $0=$ Otherwise & 0.657 & $(0.475)$ \\
\hline Abortion & $1=$ Agree with abortion, $0=$ Otherwise & 0.387 & $(0.487)$ \\
\hline Homosexuality & $1=$ Agree with gay, $0=$ Otherwise & 0.648 & $(0.478)$ \\
\hline Non-death & $\begin{array}{c}1=\text { Agree with abolishing the death penalty } \\
0=\text { Otherwise }\end{array}$ & 0.137 & $(0.344)$ \\
\hline Animal & $\begin{array}{c}1=\text { Agree with putting down stray (homeless) } \\
\text { dogs and cats, } 0=\text { Otherwise }\end{array}$ & 0.302 & $(0.459)$ \\
\hline
\end{tabular}

Note: According to the 2015 Survey Research on Attitudes toward Death Penalty and Related Values in Taiwan, total sample has 2039 observations, but the effective sample only has 1136 observations, who have completely answered all the questions for this issue. The variables of Earnings and Income are presented by individual average earnings and household average income per month in Taiwan and measured in log form.

that the distribution of $u_{i}$ is standard normal and independent across observations, MLE solves for the parameter vector $\beta$ which is most likely to have generated the data 
$\left\{y_{i}, x_{i}\right\}$. For any vector $\beta$, the probability of observing the outcome $y_{i}$ conditional on the data $x_{i}$ is:

$$
L\left(\beta \mid x_{i}\right)=\prod_{i=1}^{n} \operatorname{Pr}\left(y_{i}=0 \mid x_{i} ; \beta\right)^{1-y_{i}} \cdot \operatorname{Pr}\left(y_{i}=1 \mid x_{i} ; \beta\right)^{y_{i}}
$$

Taking a natural log to obtain:

$$
\ln L\left(\beta \mid x_{i}\right)=\sum_{i=1}^{n}\left[\left(1-y_{i}\right) \cdot \ln \operatorname{Pr}\left(y_{i}=0 \mid x_{i} ; \beta\right)+y_{i} \cdot \operatorname{Pr}\left(y_{i}=1 \mid x_{i} ; \beta\right)\right]
$$

For the probit model, the following conditions for probability hold:

$$
\begin{gathered}
\operatorname{Pr}\left(y_{i}=1 \mid x_{i} ; \beta\right)=\Phi\left(x_{i}^{\prime} \beta\right) \\
\operatorname{Pr}\left(y_{i}=0 \mid x_{i} ; \beta\right)=1-\Phi\left(x_{i}^{\prime} \beta\right)
\end{gathered}
$$

where $\Phi(x)$ is the standard normal cumulative distribution function. Substituting the above into (5) gives a conditional likelihood function of the form:

$$
\ln L\left(\beta \mid x_{i}\right)=\sum_{i=1}^{n}\left\{\left(1-y_{i}\right) \cdot \ln \left[1-\Phi\left(x_{i}^{\prime} \beta\right)\right]+y_{i} \cdot \ln \Phi\left(x_{i}^{\prime} \beta\right)\right\}
$$

The first-order condition requires that:

$$
\frac{\partial \ln L\left(\beta \mid x_{i}\right)}{\partial \beta}=\sum_{i=1}^{n} \frac{\left[y_{i}-\Phi\left(x_{i}^{\prime} \beta\right)\right]}{\Phi\left(x_{i}^{\prime} \beta\right) \cdot\left[1-\Phi\left(x_{i}^{\prime} \beta\right)\right]} \cdot \varphi\left(x_{i}^{\prime} \beta\right) \cdot x_{i}=0
$$

yielding the ML estimate $\beta$.

\section{Empirical Results}

Table 3 shows the coefficient estimates of agreement with euthanasia by probit model. First, for the benchmark individual, all explanatory variables take a value of zero. The benchmark individual in all cases is a single Fujianese woman, aged less than 30, who has informal education and disagrees with the issues of long-term imprisonment, Buddhism, divorce, abortion, homosexuality, abolishing the death penalty, and putting down stray dogs and cats. This benchmark value is reflected in the constant variable in Table 3, where the probability is:

$$
\operatorname{Pr}\left(y_{i}=1 \mid x_{i} ; \beta\right)=\Phi(-0.907)=0.182
$$

The effects on the probability of agreement with euthanasia can be calculated out for different demographic circumstances (Duncan, 2000). Holding other factors equal, how does the probability change for Hakka people (Race 2)? This situation models changes in the probability of agreement with euthanasia for Hakka people:

$$
\operatorname{Pr}\left(y_{i}=1 \mid x_{i} ; \beta\right)=\Phi(-0.907-0.301)=0.114
$$

That is, Hakka people have a lower probability of agreement with euthanasia. Therefore, if the estimated coefficients are negative, the probabilities of agreement with euthanasia decrease. If the estimated coefficients are positive, then the probabilities of agree with euthanasia increase.

Next, the estimated coefficients of Age 2, Age 3, Age 4, Age 5, Age 6, Edu 4, Edu 6, 
Divorce, Abortion, Homosexual, and Animal variables are statistically significantly positive for agreement with euthanasia as shown in Table 3. This means that older workers, people with higher educational attainment, people agreeing with divorce, abortion, homosexuality, and putting down stray dogs and cats are more likely to agree with euthanasia.

In contrast, the estimated coefficients of Race 2, Long prison, and Non-death variables are statistically significantly negative for agreement with euthanasia as shown in Table 3. This means that Hakka people, people who agree with long-term imprisonment, and persons in favour of abolishing the death penalty are less likely to agree with euthanasia.

For gender factors, Table 3 shows that the estimated coefficients of Age 3, Age 4, Age 5, Edu 2, Edu 3, Edu 4 , Edu 5, Edu 6, Divorce, and Abortion variables for men are statistically significantly positive for agreement with euthanasia. This means that older men, men with higher educational attainment, men agreeing with divorce and abortions are more likely to agree with euthanasia. In contrast, the estimated coefficient of the Non-death variable for men is statistically significantly negative for agreement with euthanasia. This means that men in favour of abolishing the death penalty are less likely to agree with euthanasia.

Moreover, Table 3 also indicates that the estimated coefficients of Age 2, Age 3, Age 4, Age 5, Age 6, Divorce, Abortion, and Homosexuality variables for women are statistically significantly positive for agreement with euthanasia. This indicates that older women, females agreeing with divorce, abortion, and homosexuality are more likely to agree with euthanasia. In contrast, the estimated coefficients of the Race 2 and Nondeath variables for women are statistically significantly negative for agreement with euthanasia. This means that Hakka women and women in favour of abolishing the death penalty are less likely to agree with euthanasia.

Furthermore, Table 4 shows the marginal effect of agreement with euthanasia. Although the results are similar to Table 3, some features are still of interest. For example, the variables of Age 2, Age 3, Age 4, Age 5, and Age 6 have larger marginal effects of agreement with euthanasia than Age 1. This means that, holding other variables constant, people in group Age 2 (aged 31 to 40) have a probability of agreement with euthanasia that is about 12.4 percentage points higher than a person in Age 1 (aged 21 to 30). Moreover, people in Age3 (aged 41 to 50) have a probability of agreeing with euthanasia that is about 20.8 percentage points higher than a person in Age 1 (aged 21 to 30). In contrast, the variable of Race 2 (Hakka) has a smaller marginal effect than Race1 (Fujianese). This result confirms that Hakka have a probability of agreeing with euthanasia that is about 7.5 percentage points lower than Fujianese. Furthermore, the variables of Long prison and Non-death variables have smaller marginal effects than otherwise. These results confirm that people agreeing with long-term imprisonment have a probability of agreeing with euthanasia that is about 5.1 percentage points lower than those disagreeing with long-term imprisonment; persons in favour of abolishing the death penalty have a probability of agreeing with euthanasia that is about 8.6 percentage points lower than those not in favour of abolishing the death penalty. 
Table 3. Probit coefficient estimates.

\begin{tabular}{|c|c|c|c|c|c|c|}
\hline \multirow{2}{*}{$\begin{array}{c}\text { Cases } \\
\text { Variables }\end{array}$} & \multicolumn{2}{|c|}{ Overall } & \multicolumn{2}{|c|}{ Males } & \multicolumn{2}{|c|}{ Females } \\
\hline & Coef. & Std. Err. & Coef. & Std. Err. & Coef. & Std. Err. \\
\hline Age 2 & $0.496^{\star \star \star}$ & $(0.145)$ & 0.334 & $(0.213)$ & $0.676^{* * *}$ & $(0.209)$ \\
\hline Age 3 & $0.831^{\star * \star}$ & $(0.162)$ & $0.571^{\star *}$ & $(0.238)$ & $1.102^{* * *}$ & $(0.234)$ \\
\hline Age 4 & $1.087^{\star \star \star}$ & $(0.180)$ & $1.139^{\star * *}$ & $(0.261)$ & $1.115^{\star * *}$ & $(0.264)$ \\
\hline Age 5 & $1.051^{\star \star \star}$ & $(0.222)$ & $0.986^{\star * *}$ & $(0.307)$ & $1.091^{* * *}$ & $(0.344)$ \\
\hline Age 6 & $0.759^{\star * *}$ & $(0.253)$ & 0.531 & $(0.326)$ & $1.466^{* * *}$ & $(0.468)$ \\
\hline Gender & 0.163 & $(0.100)$ & & & & \\
\hline Race 2 & $-0.301^{\star *}$ & $(0.141)$ & -0.032 & $(0.210)$ & $-0.583^{* * *}$ & $(0.206)$ \\
\hline Race 3 & 0.707 & $(0.489)$ & - & - & 0.456 & $(0.587)$ \\
\hline Race 4 & 0.011 & $(0.152)$ & 0.087 & $(0.217)$ & -0.068 & $(0.226)$ \\
\hline Race 5 & -0.499 & $(0.569)$ & -0.212 & $(0.702)$ & - & - \\
\hline Edu 2 & 0.602 & $(0.391)$ & $1.305^{*}$ & $(0.743)$ & 0.486 & $(0.507)$ \\
\hline Edu 3 & 0.516 & $(0.401)$ & $1.447^{\star}$ & $(0.750)$ & 0.299 & $(0.532)$ \\
\hline Edu 4 & $0.754^{\star}$ & $(0.394)$ & $1.730^{\star \star}$ & $(0.739)$ & 0.447 & $(0.527)$ \\
\hline Edu 5 & 0.640 & $(0.397)$ & $1.561^{\star \star}$ & $(0.734)$ & 0.361 & $(0.547)$ \\
\hline Edu 6 & $0.864^{\star *}$ & $(0.435)$ & $1.788^{\star \star}$ & $(0.767)$ & 0.594 & $(0.632)$ \\
\hline Earnings & 0.051 & $(0.079)$ & -0.004 & $(0.123)$ & 0.117 & $(0.115)$ \\
\hline Income & -0.081 & $(0.083)$ & -0.111 & $(0.122)$ & -0.043 & $(0.121)$ \\
\hline Long prison & $-0.201^{\star \star}$ & $(0.103)$ & -0.058 & $(0.144)$ & $-0.342^{\star \star}$ & $(0.155)$ \\
\hline Buddhist & -0.025 & $(0.114)$ & -0.186 & $(0.170)$ & 0.083 & $(0.161)$ \\
\hline Divorce & $0.484^{\star * *}$ & $(0.109)$ & $0.497^{\star * *}$ & $(0.155)$ & $0.498^{* * *}$ & $(0.162)$ \\
\hline Abortion & $1.122^{\star \star \star}$ & $(0.128)$ & $1.305^{\star * \star}$ & $(0.203)$ & $1.022^{* * *}$ & $(0.177)$ \\
\hline Homosexuality & $0.272^{* *}$ & $(0.121)$ & 0.244 & $(0.166)$ & $0.316^{*}$ & $(0.188)$ \\
\hline Non-death & $-0.345^{\star * *}$ & $(0.135)$ & $-0.415^{\star *}$ & $(0.190)$ & -0.275 & $(0.203)$ \\
\hline Animal & $0.188^{*}$ & $(0.113)$ & 0.075 & $(0.157)$ & 0.275 & $(0.174)$ \\
\hline Constant & -0.907 & $(0.867)$ & -0.685 & $(1.325)$ & -1.870 & $(1.297)$ \\
\hline $\mathrm{N}$ & \multicolumn{2}{|c|}{1136} & \multicolumn{2}{|c|}{618} & \multicolumn{2}{|c|}{510} \\
\hline Log likelihood & \multicolumn{2}{|c|}{-479.854} & \multicolumn{2}{|c|}{-246.897} & \multicolumn{2}{|c|}{-220.511} \\
\hline LR chi2 (24) & \multicolumn{2}{|c|}{286.23} & \multicolumn{2}{|c|}{165.07} & \multicolumn{2}{|c|}{135.83} \\
\hline
\end{tabular}

Notes: 1) The omitted (reference) categories: Age1 for age groups dummy variable; female for gender; Race 1 for race groups; and Edu 1 for educational groups. The variable of Race 3 was dropped and 6 observations not used in the case of males and the variable of Race 5 was dropped and 2 observations not used in the case of females. 2) ${ }^{*}$ Effect is significant at $p \leq 0.10 ;{ }^{* *} p \leq 0.05 ;{ }^{* *} p \leq 0.01$. 3) Goodness of fit: the result of Log-likelihood ratio test can reject the hypothesis that all coefficients except the intercept are 0 at the 0.01 level. Considering the Gender variable, the LR chi 2 of males and females are LR chi2 (22), respectively. 
Table 4. Probit marginal effect estimates.

\begin{tabular}{|c|c|c|c|c|c|c|}
\hline \multirow{2}{*}{$\begin{array}{c}\text { Cases } \\
\text { Variables }\end{array}$} & \multicolumn{2}{|c|}{ Overall } & \multicolumn{2}{|c|}{ Males } & \multicolumn{2}{|c|}{ Females } \\
\hline & $\mathrm{dy} / \mathrm{dx}$ & Std. Err. & $\mathrm{dy} / \mathrm{dx}$ & Std. Err. & $\mathrm{dy} / \mathrm{dx}$ & Std. Err. \\
\hline Age2 & $0.124^{* * *}$ & $(0.036)$ & 0.074 & $(0.047)$ & $0.183^{* * *}$ & $(0.056)$ \\
\hline Age3 & $0.208^{\star * *}$ & $(0.040)$ & $0.128^{\star *}$ & $(0.053)$ & $0.298^{* * *}$ & $(0.062)$ \\
\hline Age4 & $0.272^{\star \star *}$ & $(0.044)$ & $0.255^{\star * *}$ & $(0.058)$ & $0.301^{* * *}$ & $(0.071)$ \\
\hline Age5 & $0.263^{\star * *}$ & $(0.055)$ & $0.221^{\star * *}$ & $(0.068)$ & $0.295^{\star * *}$ & $(0.093)$ \\
\hline Age6 & $0.190^{* * *}$ & $(0.063)$ & 0.119 & $(0.072)$ & $0.397^{* * *}$ & $(0.126)$ \\
\hline Gender & 0.041 & $(0.025)$ & & & & \\
\hline Race2 & $-0.075^{\star \star}$ & $(0.035)$ & -0.007 & $(0.047)$ & $-0.157^{\star \star *}$ & $(0.056)$ \\
\hline Race3 & 0.177 & $(0.122)$ & - & - & 0.123 & $(0.158)$ \\
\hline Race4 & 0.002 & $(0.038)$ & 0.019 & $(0.048)$ & -0.018 & $(0.061)$ \\
\hline Race5 & -0.125 & $(0.143)$ & -0.047 & $(0.157)$ & - & - \\
\hline Edu2 & 0.151 & $(0.098)$ & $0.292^{*}$ & $(0.167)$ & 0.131 & $(0.137)$ \\
\hline Edu3 & 0.129 & $(0.101)$ & $0.324^{\star}$ & $(0.169)$ & 0.081 & $(0.144)$ \\
\hline Edu4 & $0.189^{*}$ & $(0.099)$ & $0.387^{\star \star}$ & $(0.166)$ & 0.121 & $(0.142)$ \\
\hline Edu5 & 0.160 & $(0.099)$ & $0.349^{* *}$ & $(0.165)$ & 0.097 & $(0.148)$ \\
\hline Edu6 & $0.216^{\star *}$ & $(0.109)$ & $0.401^{\star *}$ & $(0.173)$ & 0.161 & $(0.171)$ \\
\hline Earnings & 0.012 & $(0.019)$ & -0.001 & $(0.027)$ & 0.031 & $(0.031)$ \\
\hline Income & -0.020 & $(0.021)$ & -0.025 & $(0.027)$ & -0.011 & $(0.032)$ \\
\hline Longprison & $-0.051^{\star *}$ & $(0.025)$ & -0.013 & $(0.032)$ & $-0.092^{\star *}$ & $(0.041)$ \\
\hline Buddhist & -0.006 & $(0.028)$ & -0.041 & $(0.038)$ & 0.022 & $(0.043)$ \\
\hline Divorce & $0.121^{\star * *}$ & $(0.027)$ & $0.111^{\star * *}$ & $(0.035)$ & $0.134^{* * *}$ & $(0.043)$ \\
\hline Abortion & $0.281^{\star * *}$ & $(0.029)$ & $0.292^{\star * *}$ & $(0.038)$ & $0.276^{* * *}$ & $(0.045)$ \\
\hline Homosexuality & $0.068^{\star *}$ & $(0.031)$ & 0.054 & $(0.037)$ & $0.085^{\star}$ & $(0.051)$ \\
\hline Non-death & $-0.086^{\star *}$ & $(0.033)$ & $-0.093^{* *}$ & $(0.043)$ & -0.074 & $(0.055)$ \\
\hline Animal & $0.0471^{\star}$ & $(0.028)$ & 0.017 & $(0.035)$ & 0.074 & $(0.047)$ \\
\hline $\mathrm{N}$ & \multicolumn{2}{|c|}{1136} & \multicolumn{2}{|c|}{618} & \multicolumn{2}{|c|}{510} \\
\hline \multicolumn{7}{|l|}{ Predicted } \\
\hline Probability & \multicolumn{2}{|c|}{0.832} & \multicolumn{2}{|c|}{0.858} & \multicolumn{2}{|c|}{0.811} \\
\hline
\end{tabular}

Notes: The dy/dx is for discrete change of dummy from 0 to 1) The variable of Race3 was dropped and 6 observations not used in the case of males and the variable of Race 5 was dropped and 2 observations not used in the case of females. 2) Other notes are same with Table 3.

\section{Conclusion}

This paper examines the factors influencing euthanasia issues in Taiwan. The main empirical results show that older persons, people with higher educational attainment, people in favour of abolishing the death penalty and not opposing divorce, abortion, 
same-sex, and putting down homeless' cats or dogs are more likely to agree with euthanasia. In contrast, Mainlanders, who support the death penalty and long-term prison sentences, are less likely to agree with euthanasia.

Moreover, for the gender factor, older men with higher educational attainment, who approve of divorce and abortion, are more likely accept euthanasia. But those in favour of the death penalty are less likely to accept euthanasia. In addition, older women who support divorce, abortion, and same-sex relationships are more likely to use the euthanasia methods to solve their problems; but Mainlander women who support long-term prison are less likely to accept euthanasia.

Finally, considering the factors of individual earnings and family income, there are insignificant results for influencing euthanasia issues. Money or wealth may not solve the problems of life or death.

However, the 2015 Survey Research on Attitudes towards the Death Penalty and Related Values in Taiwan has limited information about the palliative and healthcare environment, human resources, the affordability of care, the quality of care and the level of community engagement. This paper only considers individual opinions and social related values for influencing euthanasia issues. A possible later analysis could include more factors of palliative and healthcare, more surveys and data sets which may deeply affect euthanasia issues.

\section{Acknowledgements}

The author would like to thank the Center for Survey Research, RCHSS, Academia Sinicafor providing the 2015 Survey Research on Attitudes towards the Death Penalty and Related Values in Taiwan

\section{References}

[1] Hung, W. (2009) An Economic Analysis of Retirement Decision in Taiwan. Durham Theses, Durham University. Available at Durham E-Theses Online.

http://etheses.dur.ac.uk/2114/

[2] Chiu, T. (2005) End-of-Life Decision Making in Taiwan. In: Blank, R.H. and Merrick, J.C., Eds., End-of-Life Decision Making. A Cross-National Study, MIT, London, 169-181.

[3] Lin, Y., Lan, C., Chu, H., Saito, Y., Liu, I. and Hurry, B. (2009) The Association between Regular Exercise and Health Life Expectancy. http://paa2010.princeton.edu/papers/101912

[4] Kuhse, H. (1992) Euthanasia Fact Sheet. Bioethics News, 11, 40. http://www.worldrtd.net/euthanasia-fact-sheet

[5] Kure, J. (2011) Good Death within Historical Context and as a Contemporary Challenge: A Philosophical Clarification of the Concept of Euthanasia. In: Kure, J., Ed., Euthanasia-The "Good Death" Controversy in Humans and Animals, InTech Publisher, Croatia, p. 7. http://dx.doi.org/10.5772/22622

[6] Economist Intelligence Unit (EIU) (2015) The 2015 Quality of Death Index: Ranking Palliative Care across the World, p. 49. http://www.economistinsights.com/healthcare/analysis/quality-death-index-2015

[7] Ministry of Health and Welfare (MHW) (2009) Healthy People 2020, p. 216. 
[8] Aitchison, J. and Silvey, S. (1957) The Generalization of Probit Analysis to the Case of Multiple Responses. Biometrika, 44, 131-140. http://dx.doi.org/10.1093/biomet/44.1-2.131

[9] Maddala, G. (1983) Limited-Dependent and Qualitative Variables in Econometrics. Cambridge University Press, Cambridge. http://dx.doi.org/10.1017/CBO9780511810176

Submit or recommend next manuscript to SCIRP and we will provide best service for you:

Accepting pre-submission inquiries through Email, Facebook, LinkedIn, Twitter, etc. A wide selection of journals (inclusive of 9 subjects, more than 200 journals)

Providing 24-hour high-quality service

User-friendly online submission system

Fair and swift peer-review system

Efficient typesetting and proofreading procedure

Display of the result of downloads and visits, as well as the number of cited articles

Maximum dissemination of your research work

Submit your manuscript at: http://papersubmission.scirp.org/

Or contact me@scirp.org 